CXXXVII. OBSERVATIONS ON THE EXTENT TO WHICH THE ELECTROMETRIC DETERMINATION OF THE [H'] OF BICARBONATE SOLUTIONS IS INTERFERED WITH BY THE PRODUCTION OF FORMIC ACID AT THE ELECTRODE.

\author{
By CHARLES JAMES MARTIN \\ AND ELIZABETH HERDMAN LEPPER.
}

From the Department of Experimental Pathology, Lister Institute, London.

(Received August 27th, 1926.)

Evans [1921], when comparing the $\left[\mathrm{H}^{\circ}\right]$ of bicarbonate solutions and of blood as estimated colorimetrically (dialysis method of Dale and Evans [1921]), with that obtained by the hydrogen electrode, found the $p_{\mathrm{H}}$ to be consistently about 0.2 lower by the latter method. He attributed this difference to the production of formic acid at the electrode and concluded that it was impossible to obtain the correct $p_{\mathrm{H}}$ of a bicarbonate solution electrically.

Formic acid is readily oxidised to $\mathrm{CO}_{2}$ and $\mathrm{H}_{2} \mathrm{O}$ in the presence of platinum black. Wieland [1912] showed that under suitable conditions the reverse reaction occurs and that a small quantity of formic acid is formed when water saturated with $\mathrm{CO}_{2}$ and hydrogen at a pressure of one and a half atmospheres is kept in presence of palladium black; the amount produced in $20 \mathrm{cc}$. of the solution of $\mathrm{CO}_{2}$ was only a few milligrams.

Bredig and Carter [1914] by increasing the pressure of hydrogen to 60 atmospheres, working at a temperature of $70^{\circ}$ and using sodium bicarbonate to fix the formic acid produced in the presence of palladium black obtained formate amounting to $75 \%$ of the bicarbonate present. They patented the process.

Evans had therefore good reason to suppose that traces of formic acid might be produced at the hydrogen electrode when working with solutions containing bicarbonates.

Warburg [1922, p. 248] criticised Evans' conclusions on several grounds. He also says: "It can easily be shown that the combined $\mathrm{CO}_{2}$ in an alkali bicarbonate solution does not decrease when treated for an hour with hydrogen in presence of platinum black." Warburg does not mention the concentration of his bicarbonate solutions nor how he determined the combined $\mathrm{CO}_{2}$.

We have elsewhere [1926] published observations showing that there is not a discrepancy such as Evans supposed between colorimetric and electrometric determinations of $p_{\mathrm{H}}$ of bicarbonate solutions provided that the 
concentration of the $\mathrm{Na}$ is the same as that in the standard phosphate solutions. As the concentration of $\mathrm{Na}$ in blood-serum and Sørensen's $M / 15$ phosphate solution of $p_{\mathrm{H}} 7 \cdot 4$ is approximately the same, colorimetric and electrometric observations should agree and Cullen and Hastings [1922], Warburg [1922], Verney and Bayliss [1923, 1926], Lepper and Martin [1926], found this to be the case. Nevertheless, we believe Evans was correct in concluding that some reduction of $\mathrm{CO}_{2}$ to formate does occur at the electrode, although the amount of formic acid formed is insufficient to account for the discrepancy between his colorimetric and electrometric results. It can only be appreciated in very dilute solutions, e.g. less than $0.005 \mathrm{M} \mathrm{NaHCO}$, but its action limits the correct determinations of $c_{\mathbf{H}}$ to solutions above this concentration.

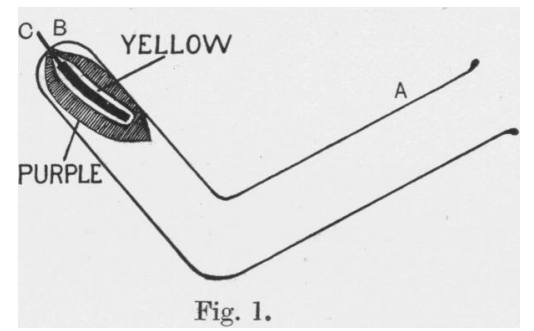

Working with a bicarbonate solution such as $0.0002 M \mathrm{NaHCO}_{3}$ shaken with room air which affords a solution of $\mathrm{CO}_{2}$ of about $0.000014 M$ and phenol red as indicator, the production of acid at the electrode can be observed in the following ways. Our first experiments were made with an electrode vessel made of a piece of hard glass tubing, $A B$, bent at an angle and closed at end $B$ (Fig. 1). The electrode, $C$, was thickly coated with platinum black. After charging the electrode with hydrogen the tube was completely filled with the bicarbonate solution containing $0 \cdot 001 \%$ phenol red; the $p_{\mathrm{H}}$ was about $7 \cdot 1$. The bicarbonate solution in immediate contact with the freshly charged electrode became lemon yellow and for $2 \mathrm{~mm}$. just outside this the full purple colour of phenol red in alkaline solution developed. If the electrode vessel was kept undisturbed the purple streamed down into the bend of the tube.

The explanation of these appearances seemed to be that $\mathrm{CO}_{2}$ was adsorbed from the bicarbonate solution by the platinum black, leaving it more alkaline for a layer of $2 \mathrm{~mm}$. surrounding the electrode. Simultaneously the film immediately in contact was rendered more acid by reduction of the adsorbed $\mathrm{CO}_{2}$ to formic acid. The effect is not due to a specific action of the electrode on phenol red, as the production of acid could be equally well shown if neutral red were used, a substance having an entirely different chemical composition from that of phenol red.

As mentioned above, the appearances could be most easily seen when a $0.0002 M$ solution of bicarbonate shaken up with room air was used. With this concentration they persisted for some hours. If $0.01 M$ bicarbonate solution saturated with $2.4 \% \mathrm{CO}_{2}$ were used the purple zone was narrower and only seen for a few minutes after the fluid came in contact with the electrode. 


\section{ESTIMATION OF $p_{\mathrm{H}}$ OF BICARBONATE SOLUTIONS 1079}

To test our interpretation we made the following experiment. An electrode $A$ (see Fig. 2) made of a circular disc of platinum $2.5 \mathrm{~cm}$. in diameter and $0.25 \mathrm{~mm}$. thick was mounted on a piece of glass tubing, $B$. The electrode was more thickly coated with platinum black on one surface, $a$, than on the other, $b$. A cylinder of hard glass, $E$, into which the electrode exactly fitted was selected and furnished with a rubber stopper pierced by two holes. Through one of these the glass tubing of the electrode was passed and adjusted so that when the cork was in position the platinum disc was two-thirds way down the cylinder. In the other hole, $G$, a piece of glass tubing of about $2 \mathrm{~mm}$. internal bore was inserted. The electrode was charged with hydrogen by making it the cathode in $10 \%$ sulphuric acid.

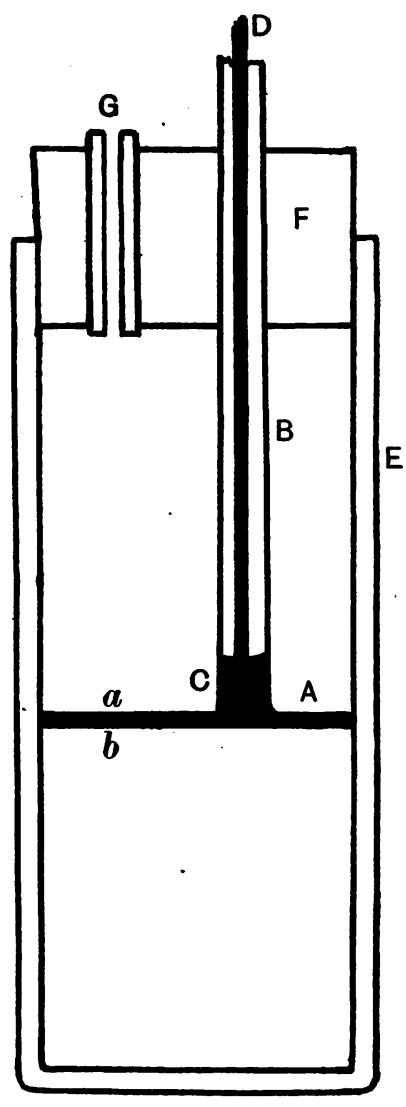

Fig. 2.

The cylinder was filled to the top with $0.0002 \mathrm{M} \mathrm{NaHCO}$ containing $0.001 \%$ phenol red and saturated with room air containing $0.035 \% \mathrm{CO}_{2}$. The resultant $p_{\mathbf{H}}$ was about 7.2 and the colour orange. The electrode was taken out of the acid, washed with distilled water for about a minute and placed in the cylinder. Sufficient washing with distilled water will secure the 
"neutrality"1 of an electrode previously saturated with hydrogen. The stopper having been pushed home the cylinder was inverted and hydrogen introduced by a capillary tube through $G$. The platinum disc was a sufficiently good fit to permit of inverting the tube without any liquid escaping between it and the glass so that the hydrogen only came in contact with one surface, $a$, of the electrode. After waiting 5 minutes for this surface to become charged with hydrogen the cylinder was placed right way up. The object of these manouvres was to secure that one surface, $a$, of the electrode should be saturated with $\mathrm{H}_{2}$ whereas the other surface, $b$, should be neutral, i.e. impregnated with neither hydrogen nor oxygen.

After a few minutes a deep purple colour developed in the fluid in immediate contact with surface $b$ and a lemon-yellow colour appeared in the fluid in contact with surface $a$. The platinum disc fitted the cylinder exactly so that diffusion was minimised and the two phases of the reaction could be observed side by side without interfering with each other. The changes of colour spread slowly out from each surface of the electrode until, after 2 hours, all the fluid in the lower half of the cylinder was purple and that in the upper half lemon yellow.

We explain these appearances as follows: both surfaces of the disc adsorbed $\mathrm{CO}_{2}$; as surface $b$ was neutral no further reaction took place and the fluid in contact with it became alkaline. At surface $a$, however, owing to the presence of $\mathrm{H}_{2}$ in the platinum black the $\mathrm{CO}_{2}$ adsorbed was reduced to formic acid and the solution in contact with $a$ became acid.

Reduction of $\mathrm{CO}_{2}$ at the electrode does, we believe, limit the use of the hydrogen electrode when dealing with very weak solutions of bicarbonate. The following calculations of $p_{\mathrm{K}_{1}}$, at $18^{\circ}$ from our determinations of the $\left[\mathrm{H}^{*}\right]$ of bicarbonate solutions of diminishing concentration show how its value slowly rises from increased activity of the hydrogen ions and then suddenly falls away between 0.002 and $0.0002 M$. This we attribute to the formation of formic acid at the electrode becoming significant at the low concentration of bicarbonate.

\begin{tabular}{|c|c|c|c|c|}
\hline \multirow[b]{2}{*}{$\underset{M}{\mathrm{NaHCO}_{3}}$} & \multicolumn{4}{|c|}{ Influence of concentration of $\mathrm{NaHCO}_{3} / \mathrm{CO}_{2}$ on $p_{\mathrm{K}_{1}}$. } \\
\hline & $\begin{array}{l}\text { Pressure of } \mathrm{CO}_{2} \\
\mathrm{~mm} .\end{array}$ & $M \mathrm{CO}_{2}$ & $\underset{\text { electrometrically }}{p_{\mathrm{H}}}$ & \\
\hline $\begin{array}{l}0.02 \\
0.01 \\
0.002\end{array}$ & $\begin{array}{l}25 \cdot 0 \\
18 \cdot 5 \\
18 \cdot 5\end{array}$ & $\begin{array}{l}0.00135 \\
0.00101 \\
0.00101\end{array}$ & $\begin{array}{l}7 \cdot 48 \\
7 \cdot 32 \\
6 \cdot 66\end{array}$ & \\
\hline 0.00002 & 0.26 & 0.000014 & 7.00 & $5 \cdot \varepsilon$ \\
\hline
\end{tabular}

1 By "neutrality" is here meant an electrode which is charged neither with $\mathrm{H}_{2}$ nor $\mathrm{O}_{2}$. If washed too long with distilled water it becomes an $\mathrm{O}_{2}$ electrode. 


\section{Conclusions.}

1. The production of an acid at the hydrogen electrode in bicarbonate solutions can be demonstrated when the concentration of bicarbonate is small by adding an indicator to the solution. Under these circumstances an acid zone can be seen immediately surrounding the electrode, enveloped by a wider alkaline zone due to adsorption of $\mathrm{CO}_{2}$ by the platinum black.

2. This production of acid does not, however, significantly affect the determination of the $p_{\mathrm{H}}$ of bicarbonate solutions until the molecular concentration is less than $0.005 M$.

\section{REFERENCES.}

Bredig and Carter (1914). Ber. deutsch. chem. Ges. 47, 541.

Cullen and Hastings (1922). J. Biol. Chem. 52, 517.

Dale and Evans (1921). J. Physiol. 54, 167.

Evans (1921). J. Physiol. 54, 353.

Lepper and Martin (1926). Biochem. J. 20, 45.

Verney and Bayliss (1923). J. Physiol. 58, 101.

- (1926). J. Physiol. 61, 448.

Warburg (1922). Biochem. J. 16, 153.

Wieland (1912). Ber. deutsch. chem. Ges. 45, 679. 